\title{
Palladium(II) Chloride Catalytic Methanolysis of Hydrazine Borane for Enhanced Hydrogen Production
}

\author{
Joe Ding Goh, ${ }^{1}$ Hooi Ling Lee ${ }^{2}$ and Yong Shen Chua ${ }^{1 *}$ \\ ${ }^{1}$ School of Chemical Sciences, Universiti Sains Malaysia, \\ 11800 USM Pulau Pinang, Malaysia \\ ${ }^{2}$ Nanomaterials Research Group, School of Chemical Sciences, \\ Universiti Sains Malaysia, 11800 USM Pulau Pinang, Malaysia \\ "Corresponding author: yschua@usm.my
}

Published online: 25 December 2019

To cite this article: Goh, J. D., Lee, H. L. \& Chua, Y. S. (2019). Palladium(II) chloride catalytic methanolysis of hydrazine borane for enhanced hydrogen production. J. Phys. Sci., 30(Supp. 2), 127-139, https://doi.org/10.21315/jps2019.30.s2.11

To link to this article: https://doi.org/10.21315/jps2019.30.s2.11

\begin{abstract}
Hydrazine borane (HB) is emerging as one of the most promising hydrogen carriers due to its high gravimetric hydrogen storage capacity (15.4 wt\%). However, thermolysis of HB suffers from slow reaction rate, foaming issue and release of unfavourable by-products such as hydrazine and ammonia which are poisons to fuel cell catalyst. To resolve these problems, instead of thermolysis, herein, methanolysis has been studied to extract hydrogen from $\mathrm{HB}$, using palladium(II) chloride, $\mathrm{PdCl}_{2}$ as catalyst. In this study, the order of the reaction, activation parameters such as activation energy $\left(E_{a}\right)$, activation enthalpy $\left(\Delta H^{*}\right)$ and entropy $\left(\triangle S^{*}\right)$ have been determined by carrying out catalytic methanolysis at different concentrations of $\mathrm{HB}, \mathrm{PdCl}_{2}$ and temperatures. Determination of true active catalyst, catalyst reuseability and pathway analysis of the reaction have also been studied.
\end{abstract}

Keywords: Hydrazine borane, methanolysis, palladium(II) chloride, hydrogen storage, reaction kinetics

\section{INTRODUCTION}

Hydrogen has been considered as one of the best alternative energy carriers to replace fossil fuel. It has higher energy density as compared with that of fossil fuel. Since hydrogen is a highly combustible diatomic gas, safe and efficient storage of hydrogen is the key challenge for its widespread application. ${ }^{1}$ Hydrazine borane (HB), $\mathrm{N}_{2} \mathrm{H}_{4} \mathrm{BH}_{3}$ which has a gravimetric hydrogen storage capacity of $15.4 \mathrm{wt} \% \mathrm{H}_{2}$ 
is a potential candidate for hydrogen storage as it has exceeded the United States Department of Energy's 2020 hydrogen storage target of $4.5 \mathrm{wt} \%{ }^{2}$

Dehydrogenation of HB can be carried out via three ways, i.e., thermolysis, hydrolysis and alcoholysis. Hydrolysis and alcoholysis of HB receive significant research attention because of their ability to produce high purity hydrogen as compared to thermolysis. ${ }^{3}$ However, due to low hydrolysis and methanolysis reaction rate, researchers have further carried out steps to increase the efficiency of hydrogen gas release which include addition of catalyst. Due to the obvious disadvantages of homogeneous catalyst in separation and its reusability, heterogeneous catalyst has received extensive attention. ${ }^{4}$ The noble metal catalysed hydrolysis of HB has been studied at room temperature and efficient hydrogen release has been achieved. It was suggested that, among all metal catalyst used, rhodium(III) chloride provided the highest catalytic activity. ${ }^{5}$ Although the reaction can be carried out at relatively milder condition and with satisfactory hydrogen release efficiency, issue related to instability of $\mathrm{HB}$ towards self-hydrolysis remains unsolved. ${ }^{5}$ Whereas in alcoholysis study of $\mathrm{HB}$, it was found that $\mathrm{HB}$ is relatively stable in methanol and did not undergo self-methanolysis. ${ }^{6}$ As reported, in the presence of nickel(II) chloride catalyst, an efficient release of hydrogen can be achieved at mild condition.

Palladium(II) chloride $\left(\mathrm{PdCl}_{2}\right)$ is a common dehydrogenation catalyst which has been used in the hydrolysis of ammonia borane and hydrazine borane, respectively. ${ }^{7,8}$ Interestingly, $\mathrm{PdCl}_{2}$ was found to be a better catalyst for the hydrolysis of $\mathrm{HB}$ as compared to $\mathrm{NiCl}_{2} \cdot 6 \mathrm{H}_{2} \mathrm{O} .{ }^{9}$ However, thus far there is no report on the employment of $\mathrm{PdCl}_{2}$ as the catalyst for the methanolysis of HB. Therefore, it is worthwhile to investigate the effectiveness of $\mathrm{PdCl}_{2}$ as compared to $\mathrm{NiCl}_{2}$ as the catalyst for methanolysis of HB.

In this present work, we investigated the efficiency of $\mathrm{PdCl}_{2}$ as the catalyst for the methanolysis of HB. It was found that the rate of hydrogen generation is second order with respect to the concentration of $\mathrm{PdCl}_{2}$ but zero order with respect to concentration of $\mathrm{HB}$. The activation parameters $\left(\mathrm{Ea}, \Delta \mathrm{H}^{\#}\right.$ and $\left.\Delta \mathrm{S}^{\#}\right)$ of the catalytic reaction have also been determined.

\section{EXPERIMENTAL}

\subsection{Materials}

Hydrazine hemisulfate salt, $\mathrm{N}_{2} \mathrm{H}_{4} \cdot 1 / 2 \mathrm{H}_{2} \mathrm{SO}_{4}(\geq 98 \%$, Aldrich), sodium borohydride, $\mathrm{NaBH}_{4}(\geq 96 \%$, Aldrich), tetrahydrofuran, THF (AR grade, QReC), methanol 
(AR grade, $\mathrm{QReC}), \& \mathrm{PdCl}_{2}(\geq 99.9 \%$, Aldrich) are used in the experiment. All chemicals are used as purchased and without any further purifications.

\subsection{Synthesis of $\mathbf{H B}$}

$\mathrm{HB}$ was prepared according to the method reported by Wu et al., using $\mathrm{NaBH}_{4}$ and $\mathrm{N}_{2} \mathrm{H}_{4} \cdot 1 / 2 \mathrm{H}_{2} \mathrm{SO}_{4}$ as precursors in the presence of THF. ${ }^{10}$ In the glove box, $0.132 \mathrm{~mol}$ of $\mathrm{NaBH}_{4}$ was first added into a $250 \mathrm{ml}$ conical flask containing $100 \mathrm{ml}$ of THF. An amount of $0.145 \mathrm{~mol}$ of $\mathrm{N}_{2} \mathrm{H}_{4} \cdot 1 / 2 \mathrm{H}_{2} \mathrm{SO}_{4}$ was subsequently added. Then, the flask was capped and transferred out from glove box. The flask was then chilled in an ice bath and placed on a magnetic stirrer for continuous stirring for three days. All the content inside the flask was separated by centrifugation. The resulting supernatant was then subjected for solvent removal to yield white powder HB.

\subsection{Structural and Chemical States Characterisations}

Structural identifications were carried out on a Bruker D8 Advance XRD with $\mathrm{Cu} \mathrm{K \alpha}, 40 \mathrm{kV}$ and $40 \mathrm{~mA}$. Liquid state ${ }^{11} \mathrm{~B}$ NMR ex-situ and in-situ nuclear magnetic resonance (NMR) experiments were carried out on a Bruker $500 \mathrm{MHz}$ spectrometer at room temperature, using $\mathrm{BF}_{3} \cdot \mathrm{Et}_{2} \mathrm{O}$ as reference at $0 \mathrm{ppm}$. Fourier transform infrared (FTIR) measurements were conducted on Perkin-Elmer System 2000 spectrometer. The chemical bonding states of Pd present at the catalyst surface was investigated by using XPS on AXIS Ultra DLD, Kratos, equipped with a hemispherical analyser and using an $\mathrm{Al} \mathrm{K} \alpha \mathrm{X}$-ray source $(1486.6 \mathrm{eV}$, the $\mathrm{X}$-ray tube working at $15 \mathrm{kV}$ and $10 \mathrm{~mA}$ ) with pass energy of $20 \mathrm{eV}$ and step size at $0.2 \mathrm{eV}$.

\subsection{Catalytic Methanolysis of HB}

In order to determine the order of reaction with respect to the concentration of $\mathrm{PdCl}_{2}, 0.5 \mathrm{M}$ of $\mathrm{HB}$ was added into a reactor, whereas concentration of $\mathrm{PdCl}_{2}$ was varied at $1.25 \mathrm{mM}, 2.50 \mathrm{mM}, 3.75 \mathrm{mM}$ and $5.00 \mathrm{mM}$, respectively. Similarly, to determine the order of reaction with respect to the concentration of $\mathrm{HB}$, the concentration of $\mathrm{PdCl}_{2}$ was kept constant at $2.50 \mathrm{mM}$ whereas the concentration of HB was varied at $0.625 \mathrm{M}, 0.500 \mathrm{M}, 0.375 \mathrm{M}$ and $0.250 \mathrm{M}$, respectively.

To determine the activation parameters, the catalytic methanolysis of $\mathrm{HB}$ with $0.5 \mathrm{M}$ of $\mathrm{HB}$ and $2.50 \mathrm{mM}$ of $\mathrm{PdCl}_{2}$ in $10 \mathrm{ml}$ of methanol were carried out at various temperatures, i.e., $30^{\circ} \mathrm{C}, 35^{\circ} \mathrm{C}, 40^{\circ} \mathrm{C}$ and $45^{\circ} \mathrm{C}$, respectively. 


\subsection{Active Catalyst and its Reusability Study}

To study the reusability of $\mathrm{PdCl}_{2}$ catalyst, catalytic methanolysis of $\mathrm{HB}$ with $0.5 \mathrm{M}$ of $\mathrm{HB}$ and $2.50 \mathrm{mM}$ of $\mathrm{PdCl}_{2}$ in $10 \mathrm{ml}$ of methanol was carried out at $45^{\circ} \mathrm{C}$. After the reaction, fresh $\mathrm{HB}$ was then added in the reactor with the used $\mathrm{PdCl}_{2}$. The process was repeated twice. After the methanolysis reaction, the catalyst was separated from the filtrate and washed with pure methanol and then air dried at room temperature. The dried powder was then sent for XPS analysis to determine the chemical bonding states of Pd present at the catalyst surface.

\section{RESULTS AND DISCUSSION}

\subsection{Structural Characterisation of Synthesised HB}

Figure 1(a) shows the ${ }^{11} \mathrm{~B}$ NMR of the synthesised HB. As can be seen, only a quartet was detected in the range of $-18.0 \mathrm{ppm}$ to $-20.0 \mathrm{ppm}$ which corresponds to the characteristic $\mathrm{BH}_{3}$ group of $\mathrm{N}_{2} \mathrm{H}_{4} \mathrm{BH}_{3}$. Furthermore, the absence of $\mathrm{BH}_{4}^{-}$of $\mathrm{NaBH}_{4}$ suggests that a complete conversion has been achieved. The presence of HB was further confirmed by XRD and FTIR characterisations (Figure 2). The XRD characterisation clearly demonstrates the presence of HB corresponding diffraction pattern without any traces of unreacted starting materials. The FTIR characterisation shows the characteristic HB functional groups which conform to those reported by Goubeau et al. and supports the molecular structure of HB. ${ }^{11}$

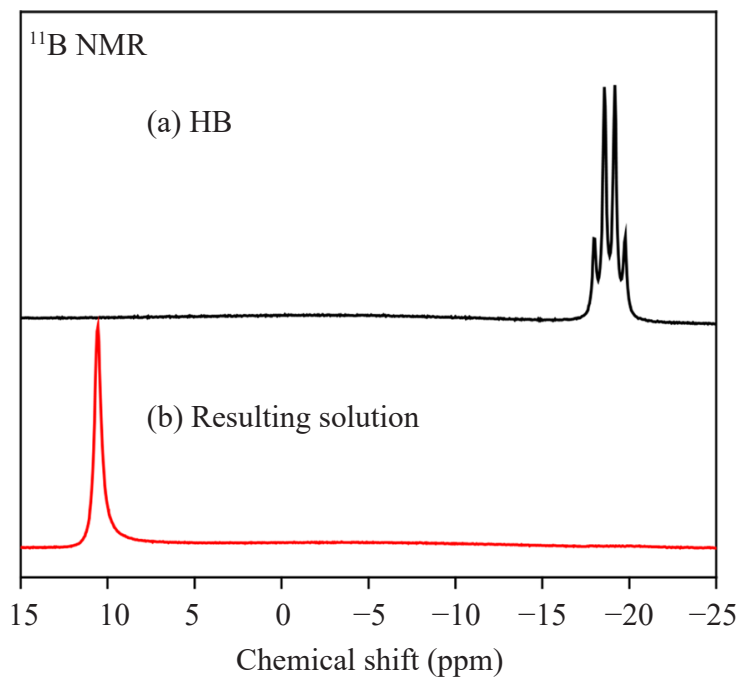

Figure 1: ${ }^{11} \mathrm{~B}$ NMR spectrum of $\mathrm{HB}$ showing (a) resulting solution after catalytic methanolysis of $\mathrm{HB}$, and (b) at room temperature. 

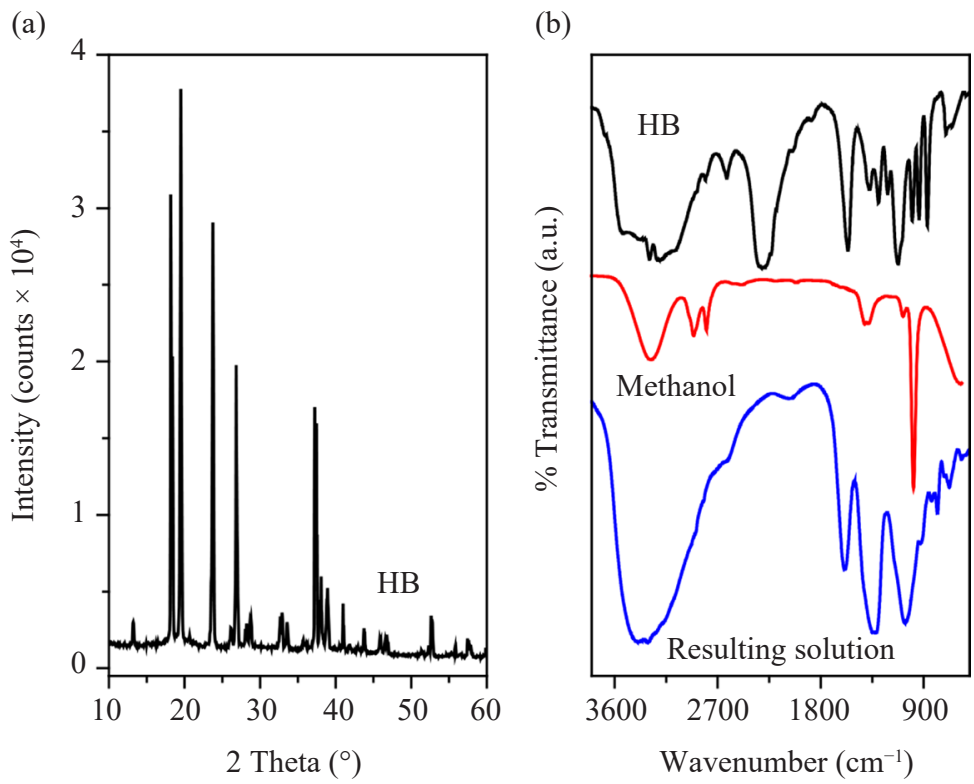

Figure 2: Illustrations of (a) XRD pattern of HB, and (b) IR spectra of HB, methanol and resulting solution after catalytic methanolysis of $\mathrm{HB}$.

\section{2 $\quad \mathrm{PdCl}_{2}$ Catalytic Methanolysis of $\mathrm{HB}$}

Figure 3 shows the plots of mol of $\mathrm{H}_{2}$ per mol of $\mathrm{HB}$ against time at different catalyst concentrations during the catalytic methanolysis of HB. From the curves, the methanolysis is a single step and spontaneous reaction at $30^{\circ} \mathrm{C}$, releasing $2.5-$ $2.8 \mathrm{~mol}$ of $\mathrm{H}_{2}$ in the reaction. The overall reaction can be expressed as follows:

$$
\mathrm{N}_{2} \mathrm{H}_{4} \mathrm{BH}_{3}+3 \mathrm{CH}_{3} \mathrm{OH} \stackrel{\mathrm{PdCl}_{2}}{\longrightarrow} \mathrm{N}_{2} \mathrm{H}_{4} \mathrm{~B}\left(\mathrm{OCH}_{3}\right)_{3}+3 \mathrm{H}_{2}
$$

When the resulting gas was bubbled into aqueous $\mathrm{CoCl}_{2}$ solution, the solution remained pink. This indicates the absence of $\mathrm{NH}_{3}$ or $\mathrm{N}_{2} \mathrm{H}_{4}$ in the gaseous products and the $\mathrm{H}_{2}$ formed is of high purity. Furthermore, the brownish $\mathrm{PdCl}_{2}$ powder turned black upon reaction, suggesting the conversion of Pd chemical state in the reaction.

As observed, the rate of the reaction rate increases with increasing concentration of $\mathrm{PdCl}_{2}$. Then, a graph of logarithmic $\ln$ rate against $\ln \left[\mathrm{PdCl}_{2}\right]$ was plotted to yield a linear regression (Figure 3 (inset)). The gradient of the linear regression line, 2.0704 indicates that the reaction is a second order reaction with respect to $\mathrm{PdCl}_{2}$ concentration. Figure 4 shows the plot of $\mathrm{mol}$ of $\mathrm{H}_{2}$ per mol of $\mathrm{HB}$ against time at different $\mathrm{HB}$ concentrations. Significant induction period was observed 


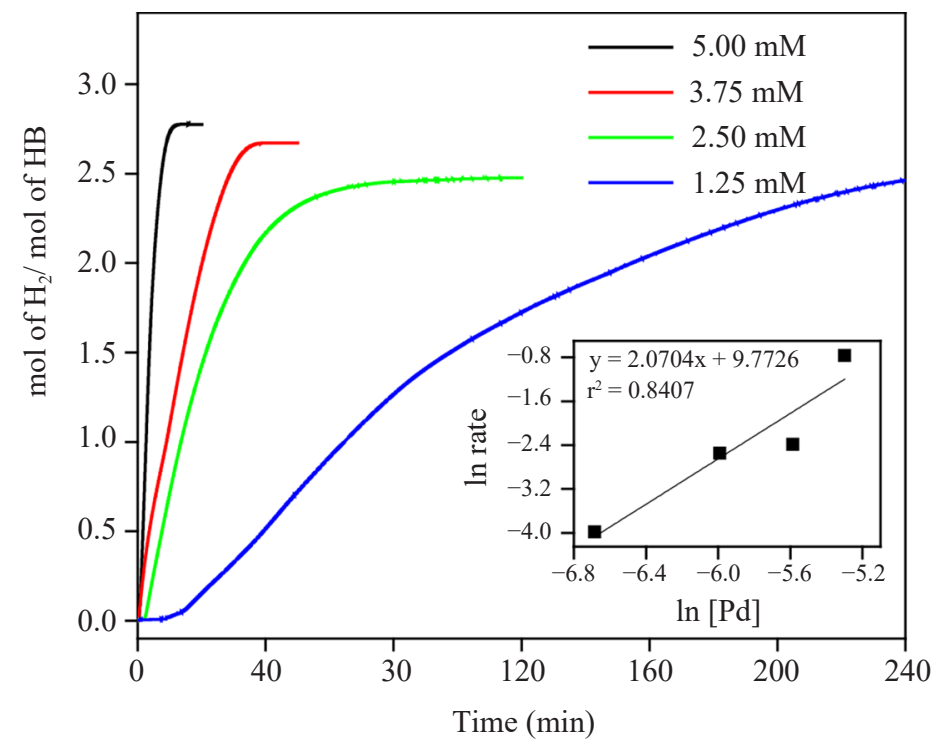

Figure 3: Methanolysis of $0.5 \mathrm{M} \mathrm{HB}$ measuring at different concentration of $\mathrm{PdCl}_{2}(10 \mathrm{ml}$ methanol at $30^{\circ} \mathrm{C}$ ). Inset is the plot of hydrogen generation rate vs. concentration of $\mathrm{PdCl}_{2}$ catalyst.

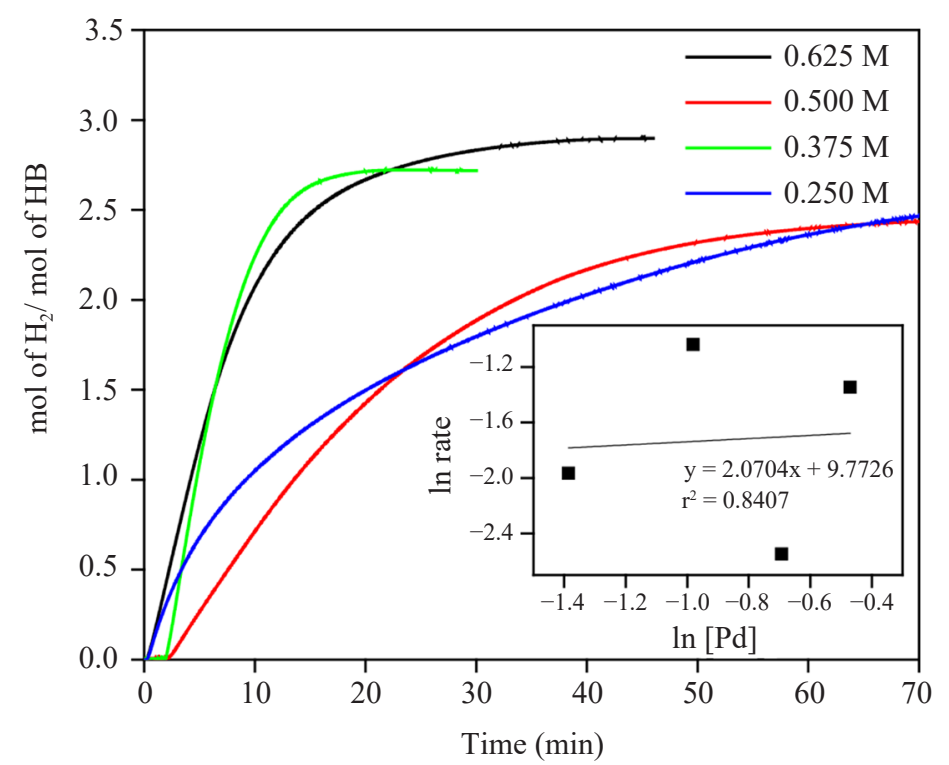

Figure 4: Methanolysis of $\mathrm{HB}$ measuring at different concentration of HB $(2.50 \mathrm{mM}$ $\mathrm{PdCl}_{2}$ and $10 \mathrm{ml}$ methanol at $30^{\circ} \mathrm{C}$ ). Inset is the plot of hydrogen generation rate vs concentration of $\mathrm{HB}$. 
when $0.375 \mathrm{M}$ and $0.500 \mathrm{M}$ of $\mathrm{HB}$ were employed, indicating possible formation of intermediate (reorientation of molecules) prior to the methanolysis process. A graph of logarithmic ln rate against $\ln [\mathrm{HB}]$ was then plotted. The gradient of the linear regression, 0.1149 indicates that the reaction is zero order with respect to $\mathrm{HB}$ concentration. These results show that the rate of reaction is dependent on concentration of $\mathrm{PdCl}_{2}$ catalyst but independent to concentration of $\mathrm{HB}$, hence, the rate law of the methanolysis reaction can be expressed as follows:

$$
r=\frac{-d[H B]}{d t}=\frac{d\left[H_{2}\right]}{3 d t}=k\left[P d C l_{2}\right]^{2}[H B]^{0}
$$

\subsection{Determination of Activation Parameters}

Figure 5(a) shows the plots of mol of $\mathrm{H}_{2}$ per mol of $\mathrm{HB}$ against time at different temperature during the catalytic methanolysis of $\mathrm{HB}$. When temperature of reaction increases, reaction rate increases. The activation energy and the pre-exponential factor were determined by using the Arrhenius equation:

$$
k=A e^{\frac{-E_{a}}{R T}}
$$

where $k$ is reaction rate constant, $E_{a}$ is activation energy $\left(\mathrm{kJ} \mathrm{mol}^{-1}\right), A$ is exponential factor, $R$ is gas constant $\left(\mathrm{J} \mathrm{mol}^{-1} \mathrm{~K}^{-1}\right)$ and $T$ is reaction temperature $(K)$.

From the Arrhenius plot in Figure 5(b), an activation energy of $E_{a}=100.3 \mathrm{~kJ} \mathrm{~mol}^{-1}$ and pre-exponential factor of $A=8.956 \times 10^{20} 1 \mathrm{~mol}^{-1} \mathrm{~min}^{-1} \mathrm{can}$ be obtained from the slope and intercept, respectively. In additions, the activation enthalpy and entropy energies were determined by using Eyring equation:

$$
k=\frac{k_{B} T}{h} e^{\frac{-\Delta H}{R T}} e^{\frac{\Delta e}{R}}
$$

where $k$ is reaction rate constant; $k_{B}$ is Boltzmann constant $\left(\mathrm{J} \mathrm{K}^{-1)} ; T\right.$ is reaction temperature $(\mathrm{K}) ; h$ is planck constant $(\mathrm{J} \mathrm{s}) ; R$ is gas constant $\left(\mathrm{J} \mathrm{mol}^{-1} \mathrm{~K}^{-1}\right) ; \Delta \mathrm{H}$ and $\Delta \mathrm{S}$ are activation enthalpy and entropy $\left(\mathrm{kJ} \mathrm{mol}^{-1}\right.$ and $\left.\mathrm{J} \mathrm{mol}^{-1} \mathrm{~K}^{-1}\right)$, respectively.

From the Eyring plot in Figure 5(c), an activation enthalpy of $\Delta \mathrm{H}^{\#}=$ $97.74 \mathrm{~kJ} \mathrm{~mol}^{-1}$ and activation entropy of $\Delta \mathrm{S}^{\#}=147.42 \mathrm{~J} \mathrm{~mol}^{-1} \mathrm{~K}^{-1}$ can be obtained from the slope and intercept, respectively. The positive value of activation enthalpy and entropy indicates enthalpy and entropy increase upon achieving the transition state, respectively, which suggests a dissociative mechanism in which the activated complex is loosely bound and about to dissociate. 
(a)

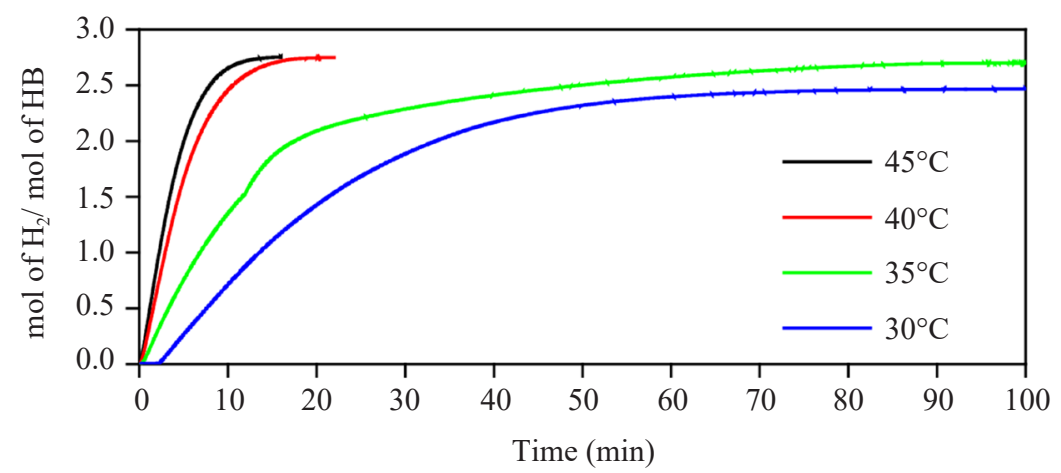

(b)

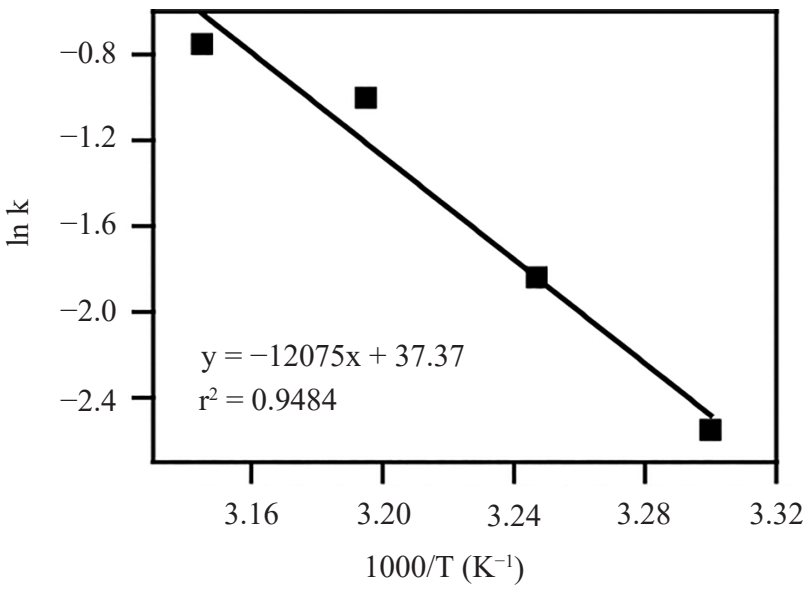

(c)

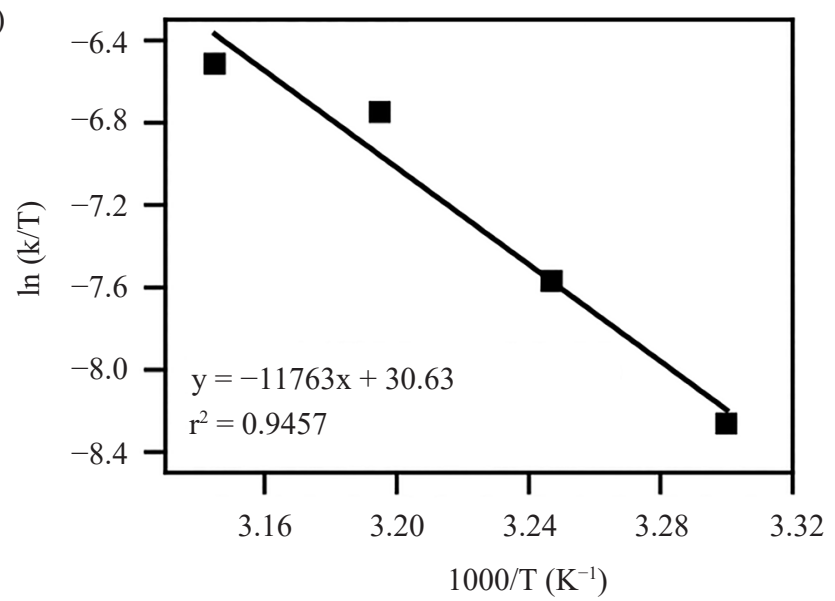

Figure 5: Illustrations of (a) methanolysis of $\mathrm{HB}$ measuring at different temperatures (2.50 $\mathrm{mM} \mathrm{PdCl}, 0.5 \mathrm{M} \mathrm{HB}$ and $10 \mathrm{ml}$ methanol at $30^{\circ} \mathrm{C}$ ), (b) Arrhenius plot, and (c) Eyring plot. 


\subsection{Methanolysis Pathway Analysis}

As shown in Figure 5(a), significant induction period was observed in the methanolysis process. In order to investigate the reaction pathway involved, in-situ ${ }^{11} \mathrm{~B}$ NMR was carried out. Figure 6 shows the time-dependent ${ }^{11} \mathrm{~B}$ NMR spectra of the catalytic methanolysis of $\mathrm{HB}$ at room temperature. From the spectra, as time increases, the quartet $\mathrm{BH}_{3}$ resonances decrease while the concentration of $\mathrm{B}-\mathrm{O}$ species increases. The spectrum shows that no $\mathrm{BH}_{2}$ or $\mathrm{BH}_{4}$ containing intermediate compounds were formed during the reaction. Therefore, the presence of induction period should be a result of deviation in experiment preparation. The $\mathrm{B}-\mathrm{O}$ resonance was shifted upfield as reaction progressed. This might be due to the formation of $\mathrm{N}_{2} \mathrm{H}_{5} \mathrm{~B}\left(\mathrm{OCH}_{3}\right)_{4}$ in which boron environment was shifted upfield as compared to $\mathrm{N}_{2} \mathrm{H}_{4} \mathrm{~B}\left(\mathrm{OCH}_{3}\right)_{3}$ as results of the additional of electron donating $-\mathrm{OCH}_{3}$ group attached to boron. $\mathrm{N}_{2} \mathrm{H}_{5} \mathrm{~B}\left(\mathrm{OCH}_{3}\right)_{4}$ is thus more thermodynamically stable in the presence of excess $\mathrm{CH}_{3} \mathrm{OH}$ (Equation 5). This result agrees with the ${ }^{11} \mathrm{~B}$ signal observed in the resulting solution upon methanolysis reaction shown in Figure 1(b) and is similar to that reported by Karahan et al. ${ }^{6}$

$$
\mathrm{N}_{2} \mathrm{H}_{4} \mathrm{~B}\left(\mathrm{OCH}_{3}\right)_{3}+\mathrm{CH}_{3} \mathrm{OH} \rightarrow \mathrm{N}_{2} \mathrm{H}_{5} \mathrm{~B}\left(\mathrm{OCH}_{3}\right)_{4}
$$

The FTIR characterisation on the residual obtained upon methanolysis reaction (Figure 2) clearly shows a broad absorbance in the range of $2700-3700 \mathrm{~cm}^{-1}$ which could be attributed to the $\mathrm{O}-\mathrm{H}$ and $\mathrm{N}-\mathrm{H}$ stretching. The presence of $\mathrm{N}-\mathrm{H}$ asymmetric bending at $1625 \mathrm{~cm}^{-1}$ further confirms the remains of $\mathrm{N}-\mathrm{H}$ bonds in the product after methanolysis. In additions, B-H stretching in the range of 2000-2500 $\mathrm{cm}^{-1}$ completely disappeared, indicating that all the $\mathrm{B}-\mathrm{H}$ has been completely consumed in the reaction.

\subsection{Reusability of Catalyst}

Figure 8 shows the degradation of the catalytic performance of the catalyst after several cycles of methanolysis. As can be seen, when the catalyst was reused in the second and third runs, there was a significant decrease in the dehydrogenation rate as shown in Figure 7. Furthermore, the dehydrogenation rate decreases with increasing number of times reused. This result clearly indicates that the product had adsorbed on the active site of the catalyst and blocked the active site, as number of times reused increases, number of active sites of catalyst decreases, hence reaction rate decreases. Washing the used $\mathrm{PdCl}_{2}$ before reusing it for the next reaction might increase the dehydrogenation rate. 


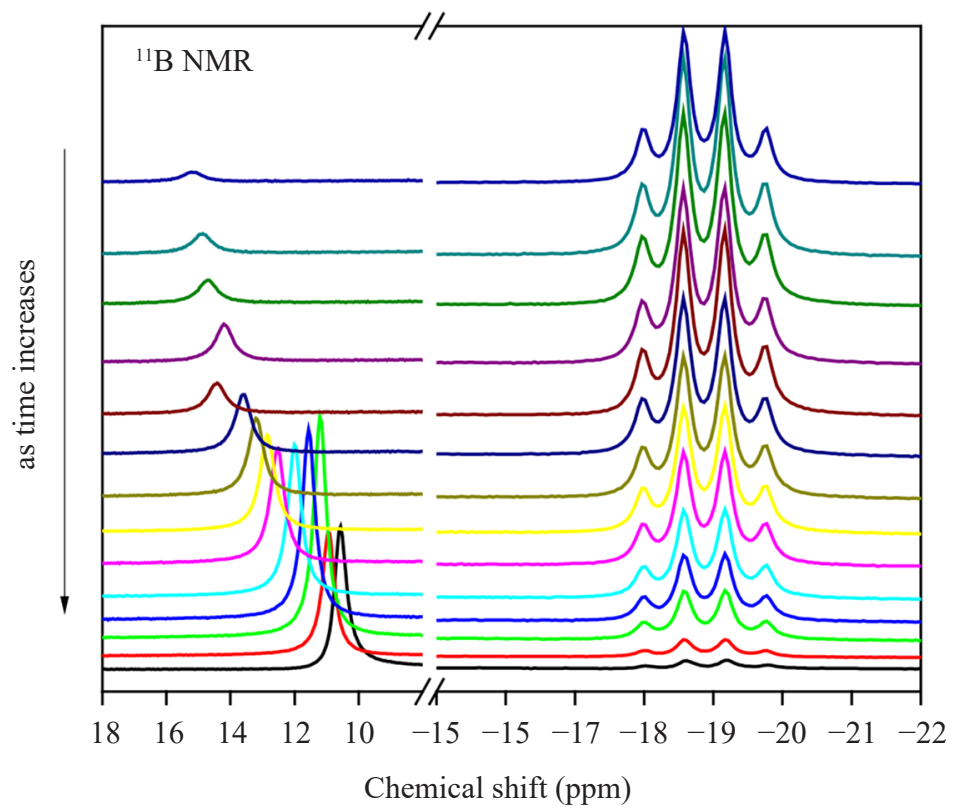

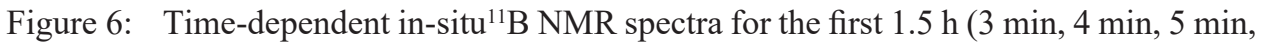
$7 \mathrm{~min}, 9 \mathrm{~min}, 15 \mathrm{~min}, 20 \mathrm{~min}, 25 \mathrm{~min}, 30 \mathrm{~min}, 40 \mathrm{~min}, 50 \mathrm{~min}, 60 \mathrm{~min}, 70 \mathrm{~min}$ and $90 \mathrm{~min}$ ) of the catalytic methanolysis of $\mathrm{HB}$ at room temperature.

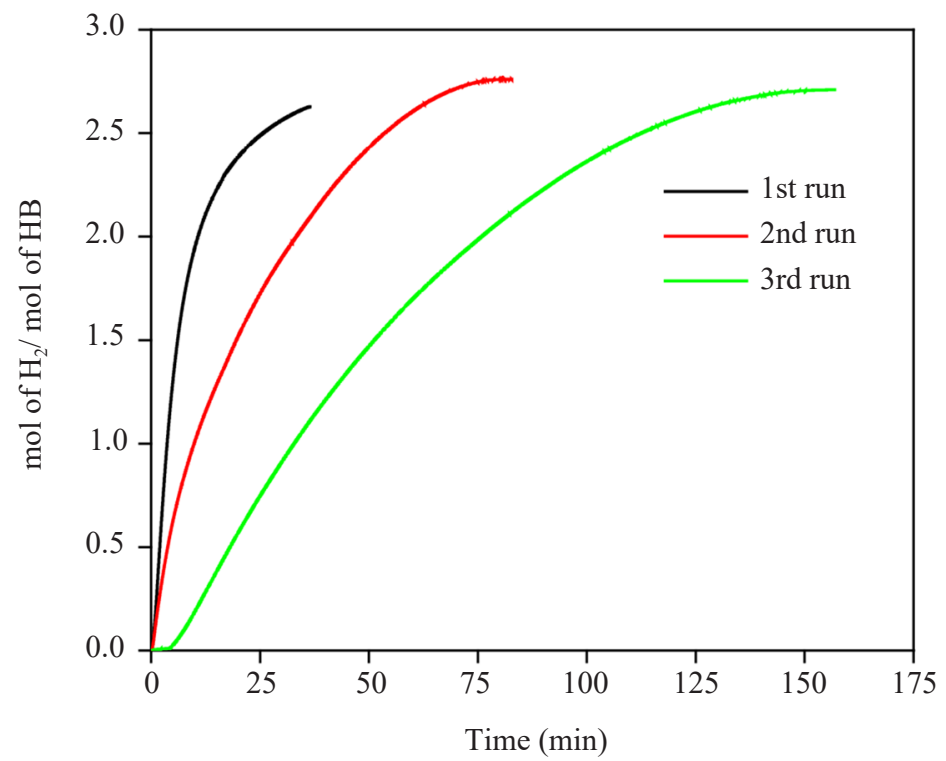

Figure 7: Methanolysis of $0.5 \mathrm{M} \mathrm{HB}$ in the presence of $2.5 \mathrm{mM} \mathrm{PdCl}_{2}$ at $45^{\circ} \mathrm{C}$. The catalyst was reused for three times under the same conditions. 


\subsection{XPS Analysis}

Figure 8 shows the XPS spectrum of $\mathrm{PdCl}_{2}$ catalyst after catalytic methanolysis reaction. $\mathrm{Pd} 3 \mathrm{~d}$ core-level spectrum can be deconvoluted by using three sets of two spin-orbit split of $\mathrm{Pd}_{5 / 2}$ and $\mathrm{Pd}_{3 / 2}$ components centred at $335.1 \mathrm{eV}, 340.4 \mathrm{eV}$, $335.5 \mathrm{eV}, 340.9 \mathrm{eV}, 336.2 \mathrm{eV}$ and $342.1 \mathrm{eV}$, respectively, attributing to metallic $\mathrm{Pd}, \mathrm{Pd}-\mathrm{B}$ species and $\mathrm{PdO}$. The presence of metallic Pd suggests that the $\mathrm{Pd}^{2+}$ in $\mathrm{PdCl}_{2}$ was reduced to $\mathrm{Pd}(0)$ during the methanolysis reaction, which is similar to those observed in the catalytic hydrolysis and methanolysis of HB by using $\mathrm{RhCl}_{3}$ and $\mathrm{NiCl}_{2}$ catalysts, respectively. ${ }^{5,6}$ The slight binding energy shift of $+0.4 \mathrm{eV}$ in $\mathrm{Pd}_{5 / 2}$ and $\mathrm{Pd}_{3 / 2}$ relative to those in metallic Pd suggests the presence of Pd-B species which may be resulted from the interaction of $\mathrm{Pd}$ and $\mathrm{BH}_{3}$ of $\mathrm{HB}$ during the activation of methanolysis reaction. A similar shift was observed when large coverage of $\mathrm{Pd}$ was deposited on amorphous boron. ${ }^{12}$ Since the catalyst can be reused as evidenced in Figure 8, it is thus plausible to deduce that $\operatorname{Pd}(0)$ is the active catalyst for the methanolysis of HB. However, the catalytic role of Pd-B species is still unclear and the formation of PdO is likely to cause the performance decay in the catalytic reaction.

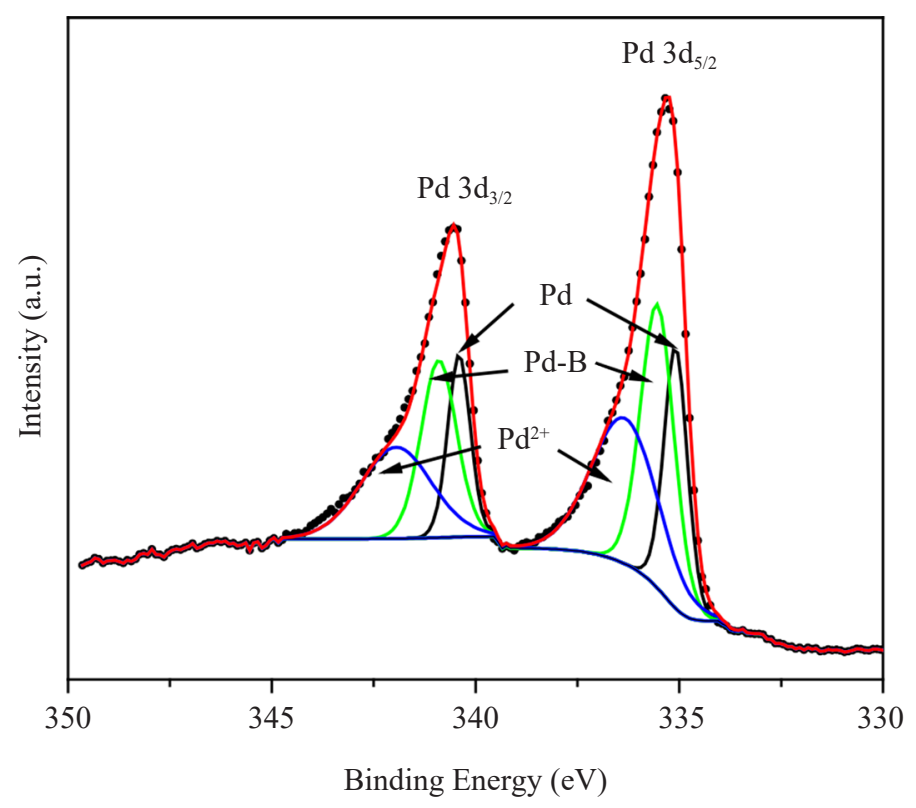

Figure 8: XPS spectrum of $\mathrm{PdCl}_{2}$ catalyst after the catalytic methanolysis reaction. 


\section{CONCLUSION}

In conclusion, $\mathrm{PdCl}_{2}$ catalytic methanolysis of $\mathrm{HB}$ is the second order with respect to concentration of $\mathrm{PdCl}_{2}$, zero order with respect to concentration of $\mathrm{HB}$ and has an activation energy of $100.3 \mathrm{~kJ} \mathrm{~mol}^{-1} \cdot \operatorname{Pd}(0)$ is the actual active catalyst in the reaction. The $\mathrm{PdCl}_{2}$ catalytic methanolysis of $\mathrm{HB}$ enables rapid and controllable hydrogen generation at room temperature. However, the decay in the catalytic performance is unavoidable due to the formation of $\mathrm{PdO}$ species on the catalyst surface.

\section{ACKNOWLEDGEMENTS}

Author Y. S. Chua acknowledges the support provided by Universiti Sains Malaysia short term grant (304/PKIMIA/6313210).

\section{REFERENCES}

1. Moury, R. \& Demirci, U. (2015). Hydrazine borane and hydrazinidoboranes as chemical hydrogen storage materials. Energies, 8(4), 3118-3141.

2. Energy.Gov. (2017). Targets for onboard hydrogen storage systems for light-duty vehicles. Retrieved 25 April 2018 from https://www.energy.gov/eere/fuelcells/ doe-technical-targets-onboard-hydrogen-storage-light-duty-vehicles.

3. Hügle, T., Kühnel, M. F. \& Lentz, D. (2009). Hydrazine borane: A promising hydrogen storage material. J. Am. Chem. Soc., 131(21), 7444-7446.

4. Lu, Z.-H. et al. (2014). Nanocatalysts for hydrogen generation from ammonia borane and hydrazine borane. J. Nanomater., 1-11.

5. Karahan, S., Zahmakıran, M. \& Özkar, S. (2011). Catalytic hydrolysis of hydrazine borane for chemical hydrogen storage: Highly efficient and fast hydrogen generation system at room temperature. Int. J. Hydr. Energy, 36(8), 4958-4966.

6. Karahan, G. et al. (2012). Catalytic methanolysis of hydrazine borane: A new and efficient hydrogen generation system under mild conditions. Int. J. Hydr. Energy, 41, 4912-4918.

7. Rakap, M. \& Özkar, S. (2011). Hydroxyapatite-supported palladium(0) nanoclusters as effective and reusable catalyst for hydrogen generation from the hydrolysis of ammonia-borane. Int. J. Hydr. Energy, 36(12), 7019-7027.

8. Jiang, H.-L. \& Xu, Q. (2011). Catalytic hydrolysis of ammonia borane for chemical hydrogen storage. Catal. Today, 170 (1), 56-63.

9. Hannauer, J. et al. (2012). Transition metal-catalyzed dehydrogenation of hydrazine borane $\mathrm{N}_{2} \mathrm{H}_{4} \mathrm{BH}_{3}$ via the hydrolysis of $\mathrm{BH}_{3}$ and the decomposition of $\mathrm{N}_{2} \mathrm{H}_{4}$. Int. J. Hydr. Energy, 37(14), 10758-10767. 
10. Wu, $\mathrm{H}$. et al. (2012). Metal hydrazinoborane $\mathrm{LiN}_{2} \mathrm{H}_{3} \mathrm{BH}_{3}$ and $\mathrm{LiN}_{2} \mathrm{H}_{3} \mathrm{BH}_{3} \cdot 2 \mathrm{~N}_{2} \mathrm{H}_{4} \mathrm{BH}_{3}$ : Crystal structures and high-extent dehydrogenation. Energy Environ. Sci., 5(6), 7531-7535.

11. Goubeau, J. \& Ricker, E. (1961). Borinhydrazin und seine pyrolyseprodukte. Zeits. Anorgan. Allgem. Chem., 310(3), 123-142.

12. Shen, D. H. et al. (1993). Chemical interaction at the Pd-B interface. J. Magn. Magn. Mater., 126(1), 25-27. 